\title{
Integrity in Scientific Research
}

\author{
Claudio Tinoco Mesquita
}

Teacher of Departamento de Medicina Clínica do Hospital Universitário Antônio Pedro, Universidade Federal Fluminense (UFF), Niterói, RJ - Brazil

"Science is composed of errors, but errors that it is right to make, for they lead step by step to the truth".

Jules Verne, Journey to the Centre of the Earth

The publication of a scientific paper is one of the biggest goals of a scientist. It is fundamental for the advancement of science, improvement of society and the sovereignty of nations. The role played by editors of biomedical journal is considered decisive for the integrity of scientific research. ${ }^{1}$ The purpose of this paper is to offer inputs about integrity and scientific fraud and discuss the initiatives that have been taken for the promotion and strengthening of good practices in research.

Brazil has seen progressive improvement in the rates of scientific publication and currently ranks $15^{\text {th2 }}$ in the ranking of SCImago countries, with more than 630,000 citable documents published in the past 20 years (Figure 1) - although there is considerable debate about the quality of the papers produced in the country, based on the low impact factor of the journals where the papers are mostly published ${ }^{2}$

The system that has led to increased academic production on a global level and also in Brazil has many merits, but it is imperfect, and incentives for researchers to publish in increasing quantities can cause abnormalities. In a recent publication, Edwards and Roy ${ }^{3}$ argue that hypercompetition for research funds and for financial and/or academic rewards has created an environment that is conducive to the cementing of scientific progress and to the rise of unethical actions. ${ }^{3}$ The quantitative metric of scientific publications is dominant in the academic

\section{Keywords}

Scientific and Technical Publications; Scientific Research and Technological Development; Scientific Integrity Review; Scientific Misconduct; Fraud; Scientometrics; Ethics; Plagiarism. world. It is the basis for workers to be hired in universities, for job promotions, awards and for obtaining financial incentives. ${ }^{3}$ The direct consequence of this environment is the increase of scientific misconduct which, according to the National Science Foundation, can be classified as follows: (1) fabrication, which is making up results in research; (2) falsification, defined as manipulating research materials, equipment or procedures, or changing or omitting data so that the research does not accurately represent the actual findings; and (3) plagiarism, which is the appropriation of someone else's ideas, processes, results, or words, without giving proper credit. ${ }^{4}$

These unethical conducts led to 291 research papers funded by the National Institute of Health (NIH) between 1992 and 2012 to be precluded from publication, at a cost of US\$ 58 million, not to mention the damage resulting from researchers and health professionals unduly using data. ${ }^{3}$ Fanelli ${ }^{5}$ has shown, in a meta-analysis, that $2 \%$ of the scientists who have been heard acknowledged that they have fabricated, falsified or modified data/results on at least one occasion; while $14 \%$ of them claim to know of data falsification in their colleagues' research studies. ${ }^{5}$ Lins and Carvalho $0^{6}$ published an analysis of fraud cases in Brazil, listing episodes of plagiarism, falsification and fabrication of results, and point out to the need for further discussion on the subject. They have also suggested the widespread adoption of good practices in research and publication, such as those published by Fundação de Amparo à Pesquisa do Estado de São Paulo (FAPESP), ${ }^{7}$ as well as the active enforcement of research integrity by regulatory agencies, such as Coordenação de Aperfeiçoamento de Pessoal de Nível Superior (CAPES) and Conselho Nacional de Desenvolvimento Científico e Tecnológico (CNPq).

Research integrity has been divided into five dimensions: (1) data handling; (2) human aspects and personal contact; (3) authoring and publishing; (4)

Mailing Address: Cláudio Tinoco Mesquita

Hospital Universitário Antônio Pedro. Rua Marquês do Paraná, 303 - Centro - Postal Code 24033-900 - Niterói, RJ - Brazil

E-mail: claudiotinocomesquita@gmail.com 


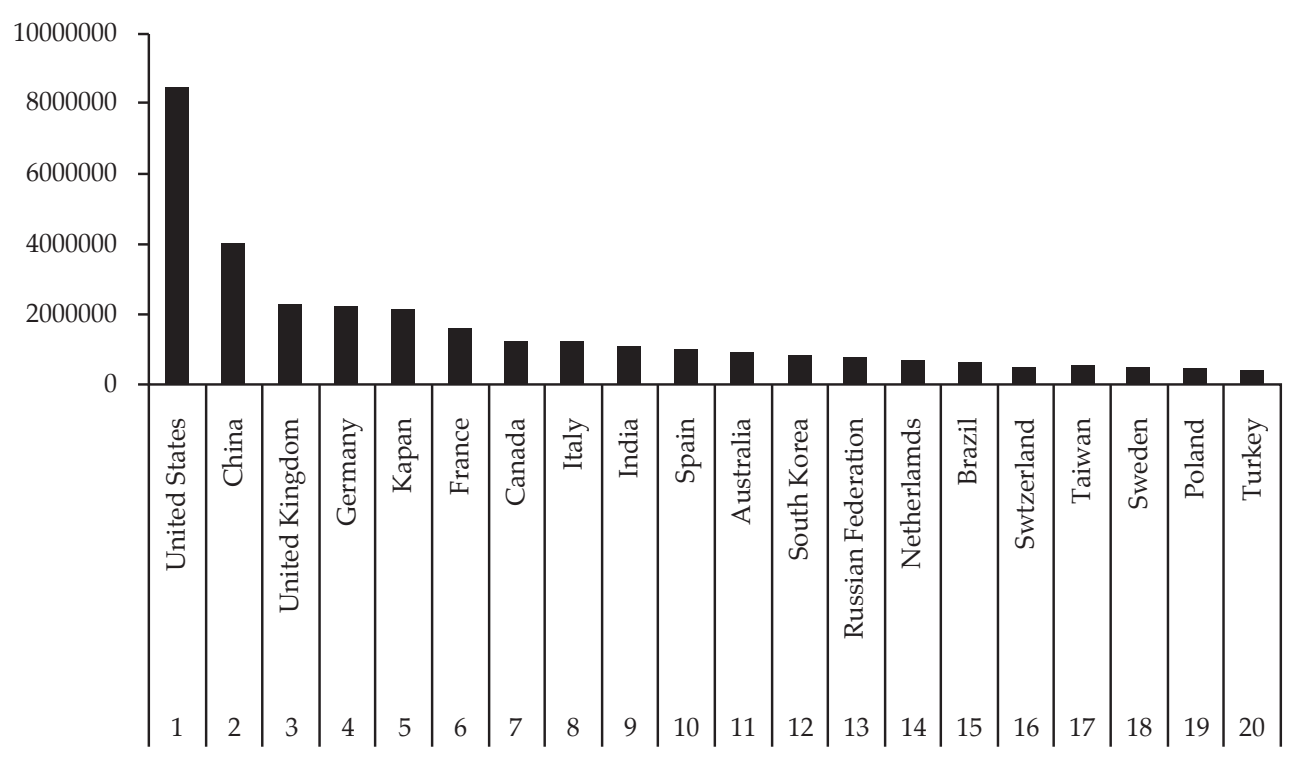

Figure 1 - Ranking of top 20 countries according to the number of citable scientific papers registered in SCImago database from 1996 to 2016. Adapted from SCImago. Retrieved on March 1, 2017. ${ }^{2}$

research sponsorship; and (5) research methodology. ${ }^{8}$ The strategies to be implemented by biomedical journals to ensure these dimensions involve the requirement of ethics committees to approve the study before it is submitted, terms and conditions on conflicts of interest specifying the specific contribution of each author, independent statistical review, plagiarism detection software and full adoption of the recommendations of the International Committee of Medical Journals Editors (ICMJE). ${ }^{9}$

Some of the most significant contributions of ICJME is the definition of who should be an author of a scientific paper, which is the individual who: (1) has helped conceiving or designing the work; or has obtained, analyzed or interpreted the research data; and (2) has participated in the drafting of the manuscript or critically revised it for important intellectual content; and (3) has given final approval to the version of the text to be published; and (4) agreed to ensure that the questions regarding the accuracy or integrity of any part of the work are properly investigated and resolved. ${ }^{9}$

Besides the importance of defining scientific authorship, the ICJME calls the attention of the scientific community to the so-called "predatory journals," which use unethical practices to attract publications that are focused on business practices. It is the authors' responsibility to evaluate the integrity of the journal to which submit their work. ${ }^{9}$

The International Journal of Cardiovascular Sciences (IJCS) fully supports and takes initiatives to promote scientific integrity, such as detailed peer review; the requirement of specifying any potential of conflicts of interest after the conclusion of each paper; the need to seek approval from the Research Ethics Committee of the institution, according to CNS Resolution 466/12 when the work involves human beings in their entirety or in parts; and the author being required to fill out a form to specify the contribution of all co-authors pursuant to the ICJME's recommendations. ${ }^{9}$ Initiatives that stimulate ethical behavior in research are encouraging, such as those proposed by the San Francisco Declaration on Research Assessment (DORA), which recommends not using any metrics, such as impact factors, in order to promote and hire individual researchers. ${ }^{10}$ Taking these actions is of the essence to strengthen the practice of delivering quality research and it is crucial for $\mathrm{t}^{\text {he }}$ society to make the most of the progress made by quality scientific research. 


\section{References}

1. De Caterina R, Griffioen AW, Porreca F. Fraud in biomedical research - the role of journal editors. Life Sci.2011;89(21-22):755-6.

2. SCIMAGO [Internet]. Scimago Journal \& Country Rank. 2017 (Online). [Cited in 2017 Mar 01] Available from: http://www.scimagojr.com/ countryrank.php?area $=3600 \&$ order $=$ h\&ord $=$ desc $\&$ year $=2015$

3. Edwards MA, Roy S. Academic Research in the 21st Century: Maintaining Scientific Integrity in a Climate of Perverse Incentives and Hypercompetition. Environ Eng Sci. 2016;34(1):51-61.

4. Kretser A, Murphy D, Dwyer J. Scientific integrity resource guide : Efforts by federal agencies, foundations, nonprofit organizations professional societies, and academia in the United States. Crit Rev Food Sci Nutr.2017;57(1):163-80.

5. Fanelli D. How many scientists fabricate and falsify research? A systematic review and meta-analysis of survey data. PLoS One. 2009;4(5):e5738.

6. Lins L, Carvalho FM. Scientific Integrity in Brazil. J Bioeth Inq. 2014;11(3):283-7.
7. FAPESP.São Paulo Research Foundation. Code of good scientific practice. São Paulo; 2012. [Cited in 2017 Mar 01] Available from: http:// fapesp.br/boaspraticas/ FAPESP -Code_of_Good_Scientific_Practice_ jun2012.pdf

8. Horbach SPJM, Halffman W. Promoting Virtue or Punishing Fraud Mapping Contrasts in the Language of "Scientific Integrity." Sci Eng Ethics. Springer Netherlands; 2016 (Online). [Cited in 2017 Mar 01]. Available from: https://link.springer.com/article/10.1007/s11948016-9858-y

9. Matheson A. The ICMJE Recommendations and pharmaceutical marketing - strengths, weaknesses and the unsolved problem of attribution in publication ethics. BMC Med Ethics (Online). BMC Medical Ethics; 2016;17(1):20. [Cited in 2017 Mar 01]. Available from: http:// bmcmedethics.biomedcentral.com/articles/10.1186/s12910-016-0103-7

10. ASCB, 2012. San Francisco Declaration on Research Assessment. Annual Meeting of the American Society for Cell Biology) pp.1-10. [Cited in 2017 Mar 01]. Available from:papers3: / / publication/uuid/1AEB2F37-D0EA4653-9E41- FBAFBA2CD42E70B. 